\title{
The results of the implementation of SAS technology for the renovation and life extension of district heating systems
}

\author{
M. V. Lukin, A. V. Ryzhenkov, A. V. Kurshakov, \\ O. V. Ryzhenkov \& A. P. Karpunin \\ National Research University "Moscow Power Engineering Institute", \\ Russian Federation, Russia
}

\begin{abstract}
The analysis of the results of large-scale work on the introduction of the facilities of complex technology, based on changing the functional surface properties of pipelines and heat power equipment using surface-active substances (SAS) technology is carried out. The volume of SAS technology realization has been specified in the heating supply systems of the Russian Federation's cities since 2003. An evaluation of the technical and economic efficiency of SAS technology, as an example of the typical elements of district heating systems based on hot water heating plants, including their boilers, heating networks, heating stations and buildings heating systems, is presented.

Keywords: surface-active substances, SAS technology, district heating system, energy efficiency, energy saving, heating, thermal points, thermal networks.
\end{abstract}

\section{Introduction}

An important problem with modern power is the need to provide a qualitative, uninterrupted and economic heat supply for consumers. In eleven regions of Russia the average annual temperatures of the external air are positive, thus, even in the warmest regions of the country the duration of the heating period is five months, and in a number of the coldest regions, heat supply is used during the whole year [1]. The quality of the services delivered with heat supply directly depend not only on economic expenses, but also on major factors such as the social stability of the population. 
In the Russian Federation the need for heat supply is provided for by about 500 combined heat and power plants, 6500 boilers with the power of more than $20 \mathrm{Gcal} / \mathrm{h}$, more than 180,000 small boilers and about 600,000 independent individual generators. The total realization of heat in the country amounts to about 2100 million Gcal/year, including the housing sector and the public sector, which consumes about 1100 million Gcal/year, whilst industry and other consumers utilize nearly 1000 million Gcal/year [2].

The current state of the majority of Russian heat supply systems dictates that they do not correspond to settlement indicators, testified by statistical data [3]. The deterioration of the main network and its parts average at $45 \%$, and the number of damages suffered by the main and parting networks exceed 1.0 damages $/ 1 \mathrm{~km}$.

The main reason for the decrease in the reliability of heating surfaces and heat exchange equipment, pipeline capacity reduction, and of work equipment as a whole, is the corrosion of functional and heat exchange surfaces and deposits caused by product accumulation. In a number of regions, natural water is used in heating supply systems without any preparation, irrespective of its initial quality. Thus, the ultimate solution for efficiency, reliability and the increase of resources operated by domestic heating supply systems, is restoration (renovation), the design of thermo-hydraulic characteristics made with subsequent improvements, and the productive increase of equipment's resistance to corrosion.

\section{The essence of SAS technology}

One of the most effective methods for an integrated approach towards the solution of the above-mentioned problems in district heating systems' objects is the introduction of a complex technology developed in NRU "MPEI" [4], based on changing the surface properties of pipelines and functional equipment using surfactants.

Owing to their amphiphilicity (consisting of two parts - the amine polar group and the nonpolar hydrocarbon amine radical), SAS molecules have surfactant properties. Surfactant molecules seek to pass over the volume of water, which leads to their oriented adsorption at the phases interface. Orientation of the polar group is always directed towards to a more polar phase. In the case when the phases are water and metal, hydrocarbon amine radicals form Langmuir's water-repellent "paling" on a metal surface. With a rather dense molecule, packing in the form of a monomolecular layer provides the guaranteed conditions for metal non-penetration by any active agent corrosion or primary oxygen connections and carbonic acid. When the amine membranes form on the heat exchange equipment of the supply systems' surfaces there is a significant change in the isoelectric potential. So for example, for carbon steels the initial potential difference averages $-380 \mathrm{mV}$ relative to the reference chlorine-silver electrode. After the formation of amine monomolecular membranes this value decreases to $-40-100 \mathrm{mV}$, i.e. the metal surface electrode potential is displaced to the positive side and to the speed of the anode reaction of ionization. At the same time it is known that the speed of deposits, in particular crystals, of a calcium carbonate accumulation directly 
depend on surface isopotential. Thus, the surfactants form a class of membranes, forming C16 amines - C20 are not only corrosion inhibitors, but also deposit inhibitors, i.e. surfactant membrane formation essentially leads to the decreasing of or even the full blocking of deposits formation.

Amines polymolecular membrane formation on a rough metal surface, first, fills asperities, as if to smooth it out, and also due to the hydrophobic surface it creates conditions for the regularization of the fluid flow in the boundary layers and makes it partially laminar (Tomson's effect). The result is a reduction in the hydraulic losses in the coolant transport. A decrease in hydraulic losses is a result of this process as a heat carrier.

In the case when functional surfaces (mainly on heat exchange surfaces) are formed by deposing in the form of metals oxides, salts and compounds of silicon, amines molecules get into the micro pores of these deposits and due to their hydration levels create excessive pressure in them and under the influence of socalled tangential forces loosen deposits, which allows for the partial or complete deletion of them from a surface in operational mode. Amines molecules have the unique property at the connection with chlorine ions (chlorides) to form an electro neutral complex, and also desorb from micro pores, micro cracks, and also from metal-surfaced chlorides which, as we know, are active stimulators of corrosion processes, including the corrosion of metals under voltage.

\section{Introduction of SAS technology to heating supply sources}

The realization of applying SAS technology to the sources and the high-level thermal networks of district heating systems was carried out using stationary automated installations (SAI) [5] (fig. 1). This allowed us to monitor the technological parameters of SAS technology and the work of the heating supply system, its preparation and the dispensing of surfactant emulsion with the parameters depending on the specific features of the heating supply system's work:

- $\quad$ equipment and pipeline's functional surfaces impurity;

- $\quad$ water and chemical mode parameters;

- $\quad$ network pumps productivity;

- actual temperature schedule of system work, etc.

The evaluation of the typical technical and economic indicators of SAS technology efficiency on the sources and the high-level thermal networks is presented for the district heating stations, "Solntsevo" and "Tereshkovo" in OJSC MUEC (Moscow United Energy Company), as an example. The economic effect was defined on the basis of a comparison of the average values and the daily consumption of gas boilers (fig. 2) and the daily electricity consumption at the district heating station (fig. 3) before the introduction of SAS technology. A comparison of the received values was carried out using identical average daily temperatures of the external air. Numerical data was provided by the staff of the operating organization on the basis of metering devices. 


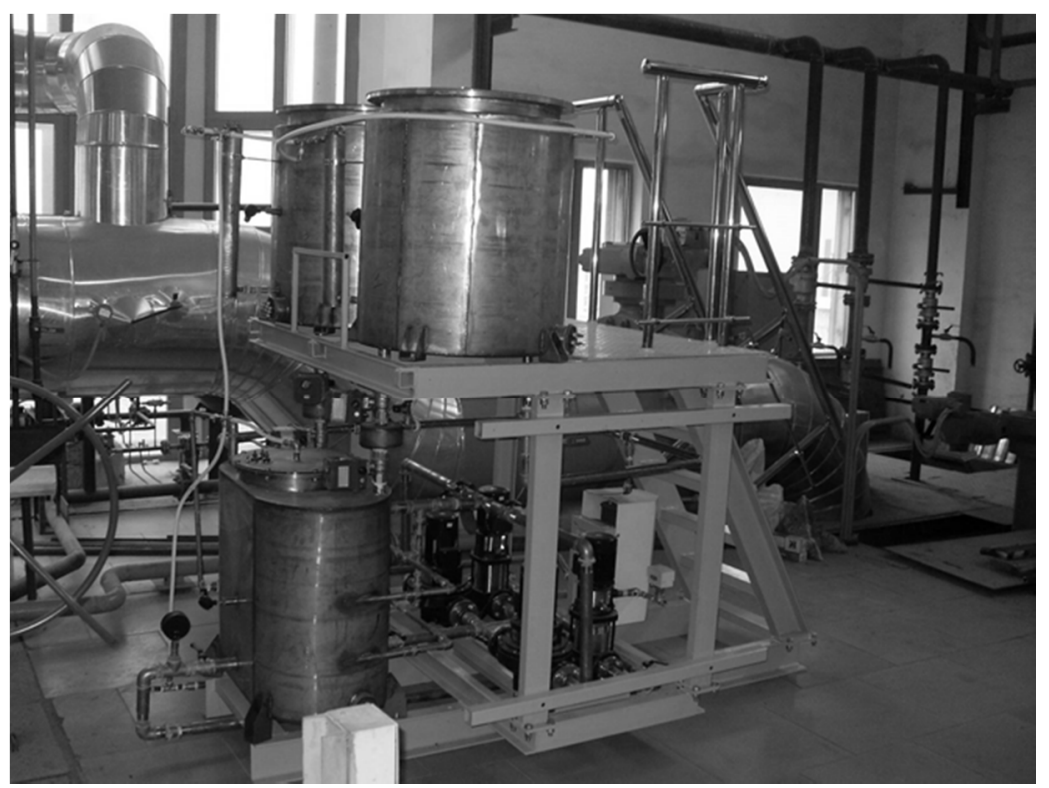

Figure 1: The stationary automated installation of SAS technology implemented in closed heating systems.



- During the work of district heating station from 28.02.2011 till 31.03.2011(before the implementation of the SAS technology)

$\triangle$ During the work of district heating station from 15.02.2012 till 04.03.2012(after the implementation of the SAS technology)

Figure 2: $\quad$ Specific average daily consumption of gas at the district heating station "Solntsevo" before and after the introduction of SAS technology. 
After the introduction of SAS technology, the gas consumption at the "Solntsevo" district heating station decreased on average by $5.2 \%$. The daily electric energy consumption at thermal stations where the dominating consumers of the electric power are network pumps, for the same temporary periods before the realization of the technology, are shown in fig. 3.

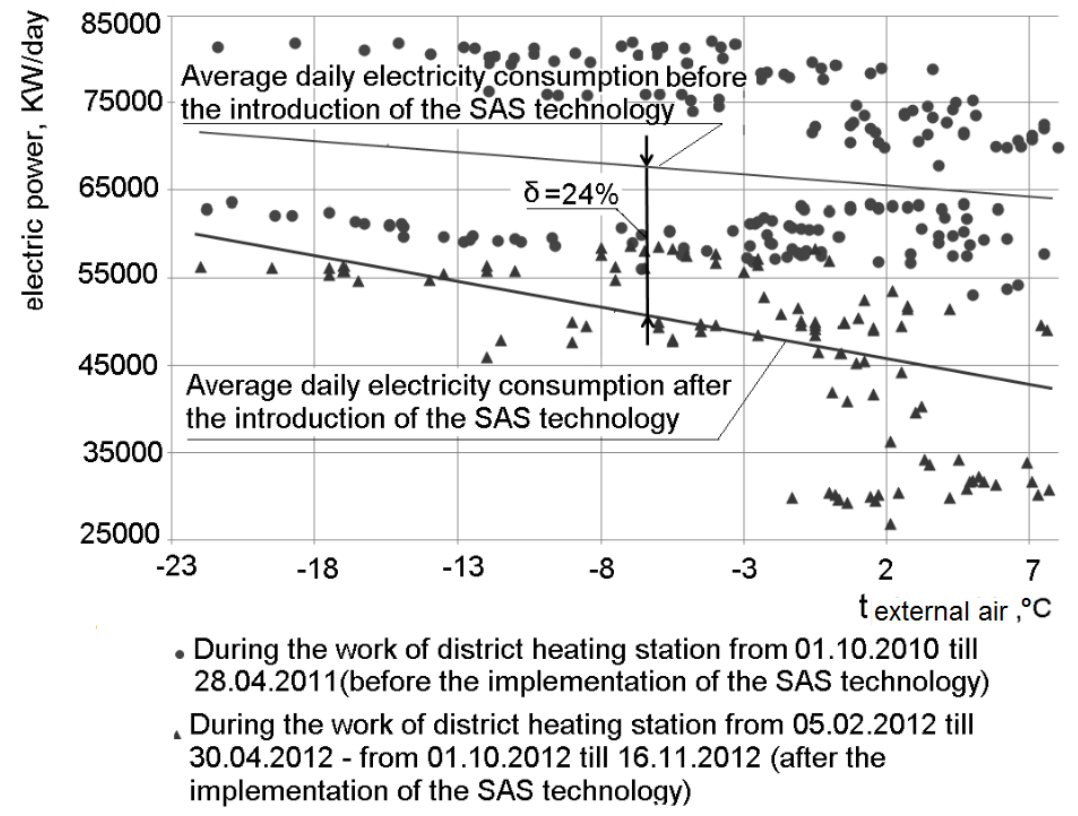

Figure 3: Total daily consumption of electric energy for the individual needs of district heating stations "Tereshkovo" and "Solntsevo" before and after the introduction of SAS technology, depending on the temperature of the external air.

After the introduction of SAS technology, the consumption of electric energy decreased by $24 \%$. A calculation of the economic effect of SAS technology introduction is made by calculating the sum of the expenses of economy sizes for natural gas purchases and the rise in electric energy owing to the decrease in their consumption during the stations' working under identical service conditions.

The experience of this technological realization shows that the general fuel consumption at stations decreases on average by $3.3 \%$ and the consumption of electric energy on the network pump drive decreases by $9.5 \%$ on average. The full payback of the technology occurs during the time period of $0.5-2$ years. Thus it should be noted that the calculation does not combine the effect from the increased reliability and the heat supply systems' resources due to the corrosion processes blocking pipelines and the internal surfaces of the equipment, and also the 
ecological effects from the decrease in polluting substance emissions owing to gas and electric energy consumption reduction.

As SAS technology realization affects all the equipment and pipelines' internal surfaces, including the high-level thermal networks' surfaces of the district heating systems, a hydrophobic protective membrane is formed. A high level of surface water repellence is confirmed by looking at the wetting regional corner values, which produces $135-145^{\circ} \mathrm{C}$.

After introducing SAS technology, an assessment of the changing of the samples' internal surface corrosion resistance and membrane formation was carried out using an electrochemical method, with the use of potentiostatgalvanostat "IPC Pro M".

The results of the conducted research showed that the speed of metal corrosion after SAS technologies realization decreased by more than 15 times, which testifies to the almost full blocking of heat supply systems' equipment and pipelines surfaces' internal corrosion processes.

\section{The introduction of SAS technology to thermal points}

The principal equipment used for the thermal points of residential and public buildings is heat exchangers, which provide the heating of the hot water supply and of heat carriers. During the use of equipment, the products of corrosion accumulates on heat transfer surfaces. This process has a negative effect on the efficiency and reliability of the equipment. SAS technology realization, providing the surface passivation of lamellar, shell and tube heat exchangers, allows for the repeated intensity reduction of deposit formation [6]. The essential factor influencing the applicability of SAS technology in natural conditions is the thermal and hydro mechanical stability created on surfactants' molecular layers and the equipment's' functional surfaces. The practice of the application of such technologies in district heating systems showed us that in most elements of the various equipment (boilers, the main and parting pipelines, thermal devices, pumps, fittings) the surfactants membrane is steady and does not collapse within three years at least, which is confirmed by taking direct measurements of the surfactants' specific sorption and also the degree of surface water repellency. Fig. 4 shows the photos of heat exchange surfaces in 3.5 years of operation, with surfactants and without, operated in identical conditions.

\section{SAS technology introduction in the heating systems of buildings and constructions}

As an example of SAS technology efficiency in relation to buildings' heating systems, a description of the technological realization process for the heating system renovation of the comprehensive high school No. 42 of Vorkuta is given [7]. The data analysis of the heat consumption for 2009-2010 showed that the school heating systems' actual thermal power did not exceed $70 \%$ of the design 

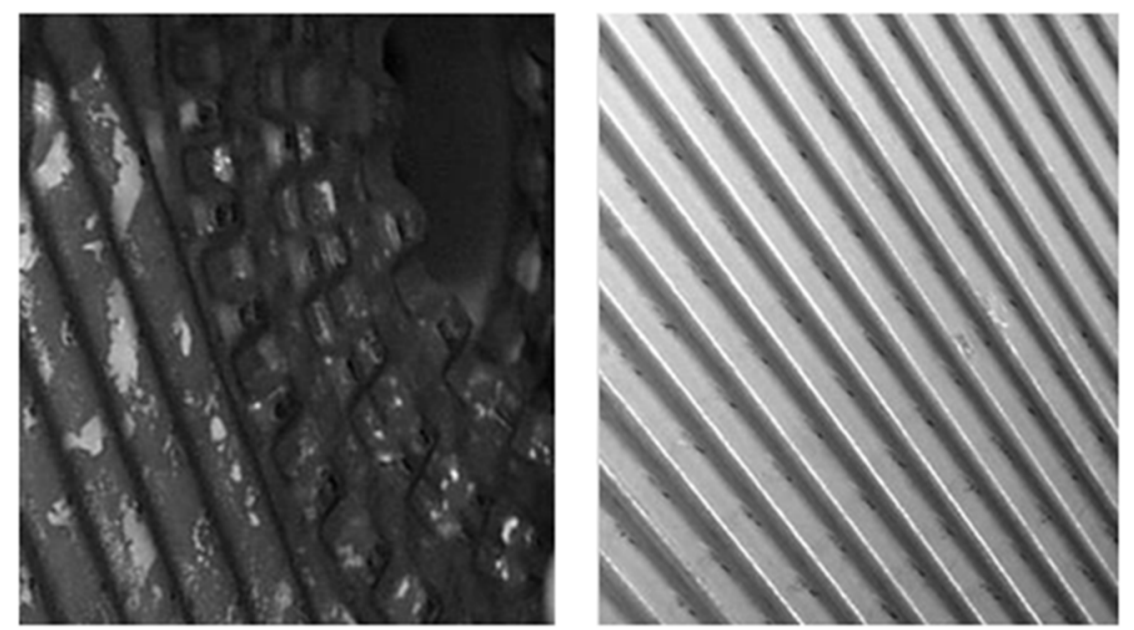

Figure 4: $\quad$ Photos of the lamellar heat exchanger plate operated for three years in a regular mode (left) and after SAS technology realization (right).

value. By looking at the results of the research, the main reason for low heat removal is a large volume of thermo-barrier deposits, which have been formed on heating device surfaces during the working of the system. For SAS technology realization, a mobile technological complex was specially developed, which is made up of the following parts: mobile installation (fig. 5), chemical analysis and diagnostic equipment. The basic purpose of mobile installation is to act as a settlement to the concentration surfactants' water emulsion preparation, providing the conditions for the surfactants' adsorption on pipelines and heating devices' internal surfaces, the removal of sawn-off deposits from heating systems and the formation of the molecular protective surfactants' membrane.

The quality standard of the heating devices' overall performance as a result of SAS technology application was received at the thermo vision shooting, which has been carried out before work performance (fig. 6) at identical parameters of the heat carrier and air temperature. On the basis of heating devices, heat pattern analysis established that, as a result of the work, heat carrier circulation through 10 heating devices working for $5-10 \%$ of the design capacity was restored, the average temperatures on all heating device surfaces increased by $1-8^{\circ} \mathrm{C}$, and the temperature fields were leveled. In particular, the average temperature of the heating devices surface located in the school library increased from $36^{\circ} \mathrm{C}$ to $46^{\circ} \mathrm{C}$.

The quantitative assessment of the school heating systems' effectiveness was received upon termination at the heating period of 2010-2011. The thermal power of the system as a result of SAS technology introduction increased by $15-25 \%$ at the identical parameters of the heat carrier on input into the heating system (temperature and an expense) and the temperatures of external air, thus heat carrier temperature, in the return pipeline decreased on average by $2^{\circ} \mathrm{C}$. 


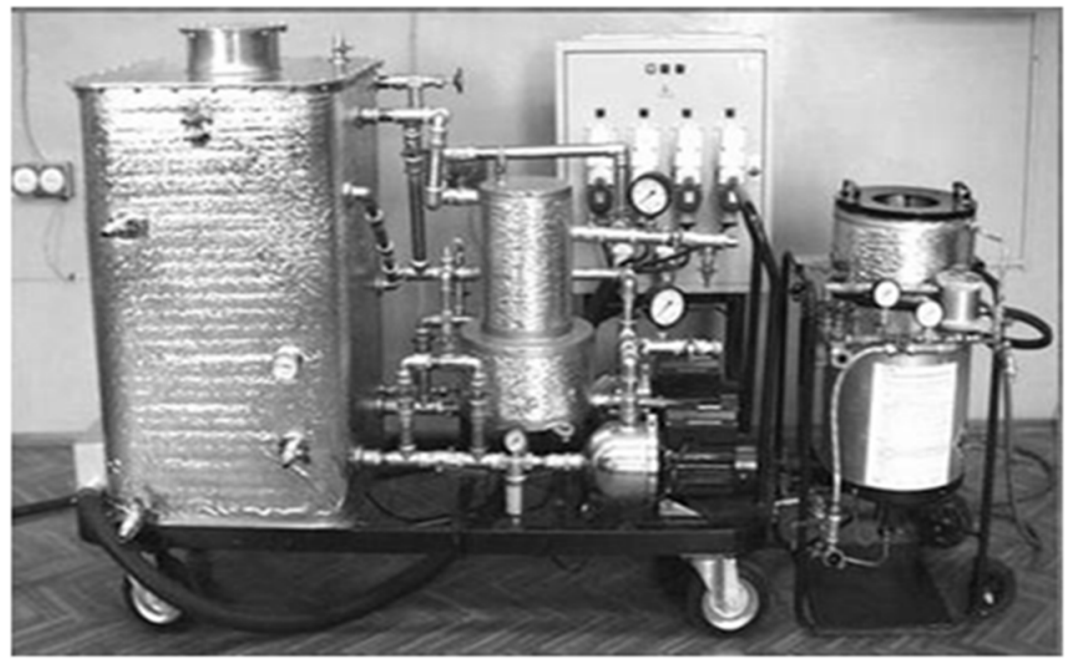

Figure 5: General view of mobile installation.
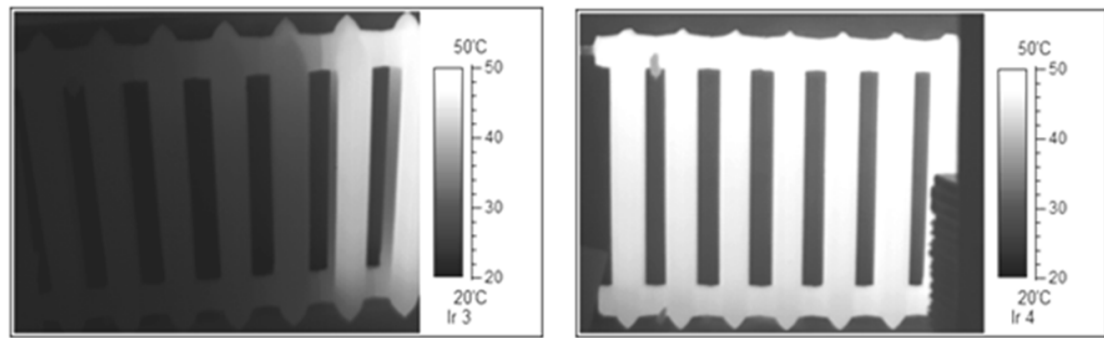

Figure 6: The heat pattern of school heating system devices surfaces before and after SAS technology introduction.

\section{Conclusion}

The results we received allow us to state that there was a high degree of efficiency in the use of SAS technology for the whole range of the systems' equipment and for the pipelines of the centralized heat supply from the source to the heat consumption systems, irrespective of their state, service life and service conditions.

\section{References}

[1] Nekrasov, A.S., Senjik, Y.V., Voronina, S.A. \& Semikashev, V.V. "Studies on Russian Economic Development”, No. 1, pp. 30-43, 2011.

[2] “Energy Saving”, No. 4, 2003. 
[3] Power energy strategy of Russia for the time till 2030. It is approved as the order of the Government of the Russian Federation of November 13, 2009 No. 1715 r.

[4] Ryzhenkov, V.A., Pogorelov, S. I., Lukin, M. V. Patent for the invention of RU No. 2323390 of 07.11.2006.

[5] Ryzhenkov, A.V., Kurshakov, A.V., Lukin, M.V., Pogorelov, S. I., Likhachev, A.N., Pulner, I.P. \& Hrityuk, T.N. "Energy saving and water treatment", No. 6, 2013.

[6] Lukin, M.V. “Chief Power Engineer”, No. 9, pp. 50-56, 2011.

[7] Rizhenkov, V.A., Volkov, A.V. \& Lukin, M.V. "Thermal Engineering”, No. 6, 2012.

[8] Ryzhenkov, V.A., Pogorelov, S. I., Lukin, M. V. Patent for the useful model RU No. 111538 of 31.05.2011. 